Reprod. Nutr. Dévelop., 1988, 28 (2 B), 349-364.

\title{
Timing of puberty by photoperiod
}

\author{
D. L. FOSTER, F. J. P. EBLING, L. E. CLAYPOOL
}

\begin{abstract}
Reproductive Endocrinology Program, Consortium for Research in Developmental and Reproductive Biology.

Departments of Obstetrics \& Gynecology and Biology

The University of Michigan, Ann Arbor

Michigan 48109-0404 U.S.A.
\end{abstract}

\begin{abstract}
Summary. Photoperiod cues play an important role in the timing of puberty in the female lamb. Removal and replacement of photoperiod cues by denervation of the pineal gland and timed melatonin infusions, respectively, indicate that the pathway for transmission of photoperiod information develops well before puberty. This is reinforced by manipulation of artificial photoperiods during various periods of development. Such approaches reveal that even in the first few weeks of life, the pattern of melatonin secretion accords with daylength and modulates prolactin secretion. Several months later, after internal, growthrelated cues indicate that sufficient body size has been achieved to initiate reproduction, photoperiod history is used as an important predictor of reprociuctive success, and thus, whether puberty should occur. In the female spring-born lamb, the decrease in daylength in autumn is the critical cue for the initiation of estrous cycles. Experimentally, this may be achieved by surgically disrupting the pathway for transmission of photic cues after appropriate long-day exposure. in the autumn-born lamb and in the slowly growing lamb, sexual maturation may be masked by the transition into seasonal anestrus the following spring. In these young females, a decreasing photoperiod or "removal of long days " (surgical) is not necessary for puberty the following autumn. Sufficient photoperiod history may be acquired in such lambs that they enter puberty as a consequence of becoming refractory to the long days of summer. We hypothesize that the phenomenon of refractoriness reflects the expression of an innate rhythm of reproductive activity and that changes in daylength experienced early in life serve to synchronize this rhythm with the seasonal envirunment.
\end{abstract}

\section{Introduction.}

The ewe lamb, much like female offspring of other seasonal breeders, must attain sufficient body size in the appropriate season to meet the demands of the first pregnancy. We recently reviewed our knowledge of the neuroendocrinology of puberty in the female sheep and how internal and external inputs to the brain integrate to modulate the timing of the increase in frequency of $\mathrm{LH}$ secretion which underlies the pubertal transition (Foster et al., 1985, 1986 ; Foster, 1987). 
This chapter identifies recent advances in understanding how the external cue, photoperiod, conveys information about season; our laboratory uses the Suffolk breed.

Photoperiod as a seasonal determinant of puberty. - Two main approaches demonstrate that photoperiod is important in timing puberty, namely alteration in onset of reproductive activity by a) disruption of pathways that convey photoperiod information and $b$ ) manipulation of photoperiod. In the lamb, as in the adult, the pattern of pineal melatonin secretion transduces information about day length into a humoral signal (Yellon and Foster, 1986 ; Foster et al., 1987a, 1987b). Denervation of the pineal gland by superior cervical ganglionectomy abolishes the normal nocturnal rise in melatonin secretion (fig. 1, insets). Whereas spring-born lambs normally begin reproductive cycles at 30-35 weeks of age, lanibs ganglionectomized at 6 weeks of age do not (fig. 1). Ovulations finally begin during the second year at more than twice the normal age (S. M. Yellon and D. L. Foster, unpublished). Removal of the pineal gland produces similar results in that pinealectomy of 10 -week-old lambs also delays puberty (Kennaway et al., 1985).
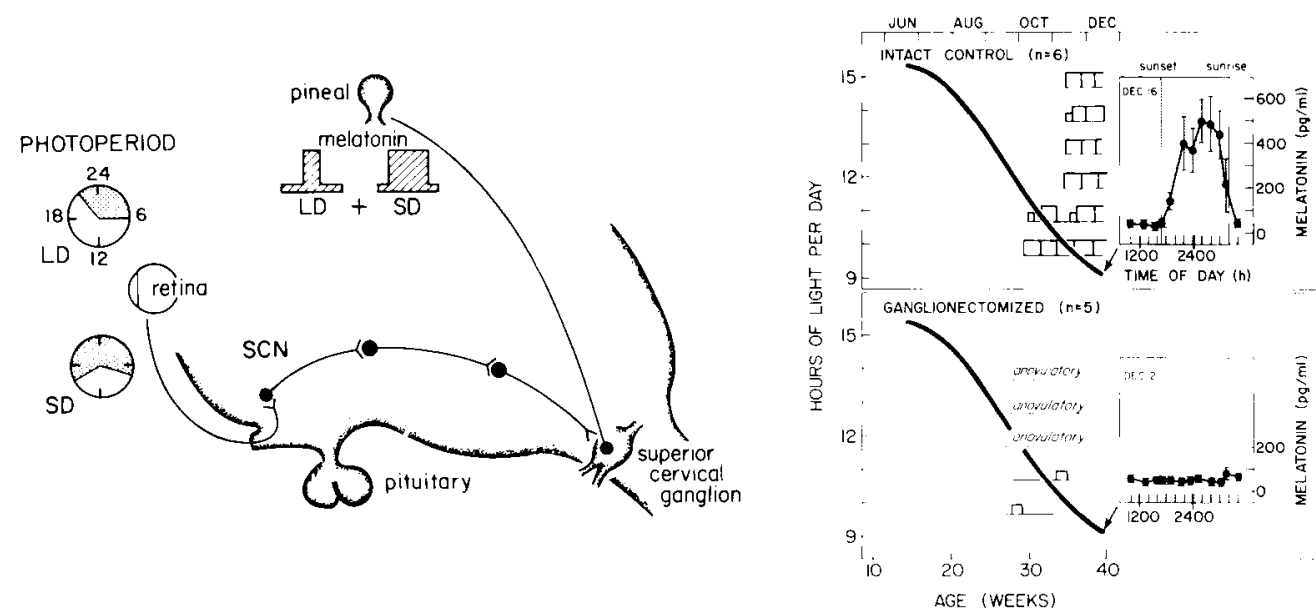

FIG. 1. - Left. Pathway for transmission of photoperiod information. Right. Onset of reproductive cycles in natural photoperiod in Suffolk lambs with (top) normal or (bottom) sympathetically denervated ( 6 weeks of age) pineal glands. Each horizontal line shows data for an individual female with large and small blocks representing normal and short luteal phases, respectively. Insets are 24-hour patterns of circulating melatonin (mean \pm SEM); shaded area is dark phase of the photoperiod. Modified from Foster et al. (1986).

In the presence of a functional system for transmission of light information, artificial photoperiod can be used to time puberty. This was first convincingly demonstrated in the autumn-born lamb (Foster, 1981). In contrast to the springborn female which begins its first reproductive cycles between 25 and 35 weeks 
of age, the autumn-born lamb remains acyclic until about one year of age (fig. 2, middle). Although it attains the appropriate age and size for puberty during the long days of the summer anestrous season, reproductive activity begins during the decreasing daylength of the autumnal breeding season. Exposure of autumnborn lambs to a seasonally reversed photoperiod prevents this delay; when such females are raised from birth in an artificial photoperiod with an annual cycle simulating that had they been born in spring, the age of puberty is restored to the normal range for spring-born females (fig. 2, bottom).
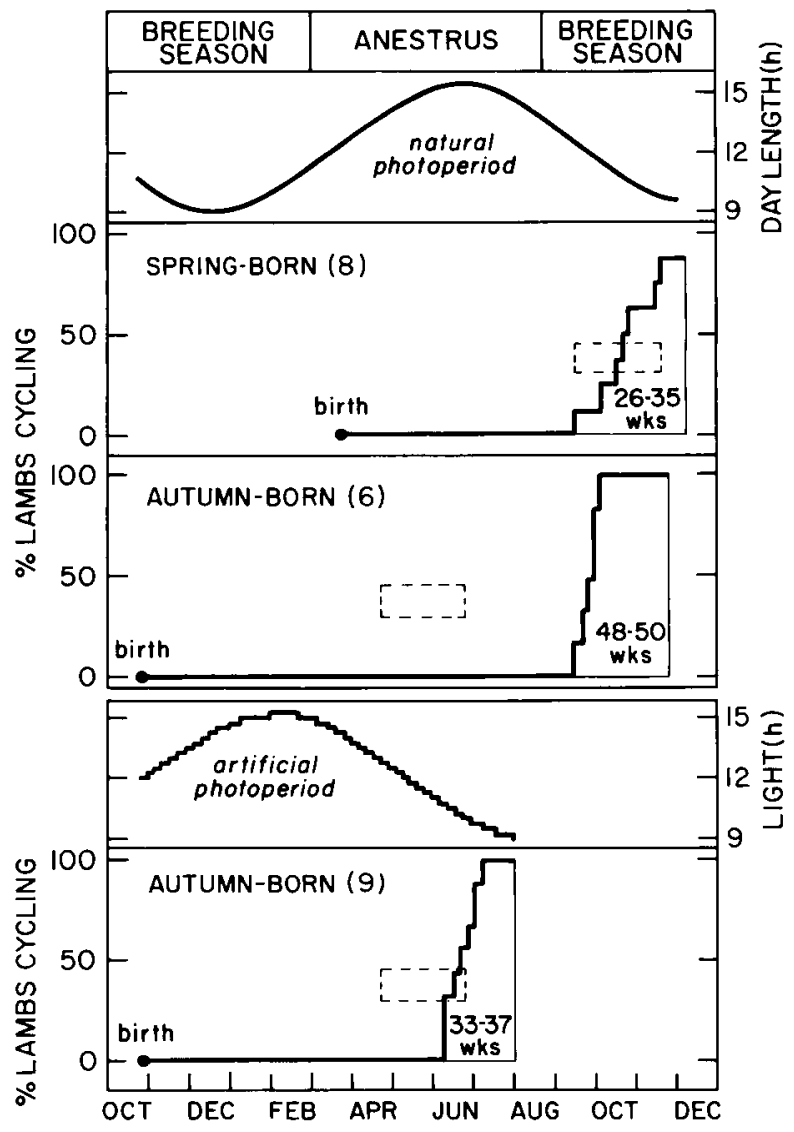

FIG. 2. - Initiation of reproductive cycles in natural photoperiod in spring-born (March) and autumnborn (October) Suffolk lambs (upper panels) and in an artificial, seasonally reversed photoperiod in autumn-born lambs (lower panels). From Foster and Ryan (1981).

Photoperiod determinants timing puberty and breeding season differ. Although temperature and other environmental variables were not controlled in either studies of disrupting pineal gland function or manipulation of light/dark cycles, we infer that photoperiod is a primary environmental cue for the timing of puberty in the female lamb. Similar conclusions have been made using comparable approaches in studies concerning the nature of seasonal cues which time reproductive transitions in the mature female sheep (Karsch et al., 1984). However, before further consideration of which aspects of the annual photoperiod are used as important external determinants for first ovulation, a 
fundamental difference must be recognized about the photoperiod requirements for the timing of puberty in the lamb and onset of the breeding season of the adult ewe. Recently Robinson et al. (1985) have suggested that the ewe normally begins its breeding season as a consequence of becoming unresponsive (" photorefractory ") to the long day lengths of late summer. When adult females were allowed to experience natural photoperiod until the summer solstice and were then continually maintained on a long-day photoperiod equivalent to that of the summer solstice, the onset of the breeding season was unchanged; it occurred at the same time as that in controls kept on a simulated natural photoperiod. That study offers convincing evidence that the phenomenon of long-day photorefractoriness could account for the initiation of the breeding season. In the spring-born lamb, such a mechanism cannot account for photoperiod regulation of the pubertal transition. This conclusion derives from application of such a "solstice hold " photoperiod approach to the lamb (fig. 3). Pairs of twin female lambs and their mothers were maintained from the summer solstice on artificial photoperiod; the mother and one twin of each pair was kept on unchanging long days while the other twin experienced a decreasing daylength simulating natural conditions. In the absence of a decrease in day length, the mothers, as expected, exhibited reproductive activity at the usual time. The daughters did not. Sexual maturity was markedly delayed in comparison to that in lambs in decreasing artificial daylength which entered puberty normally. Thus, the photoperiod requirements of the lamb and adult differ. A decrease in photoperiod is necessary for the normal timing of puberty in the sexually immature sheep born in the spring, whereas mature, seasonally anestrous ewes can initiate the breeding season in the absence of shortening daylengths.

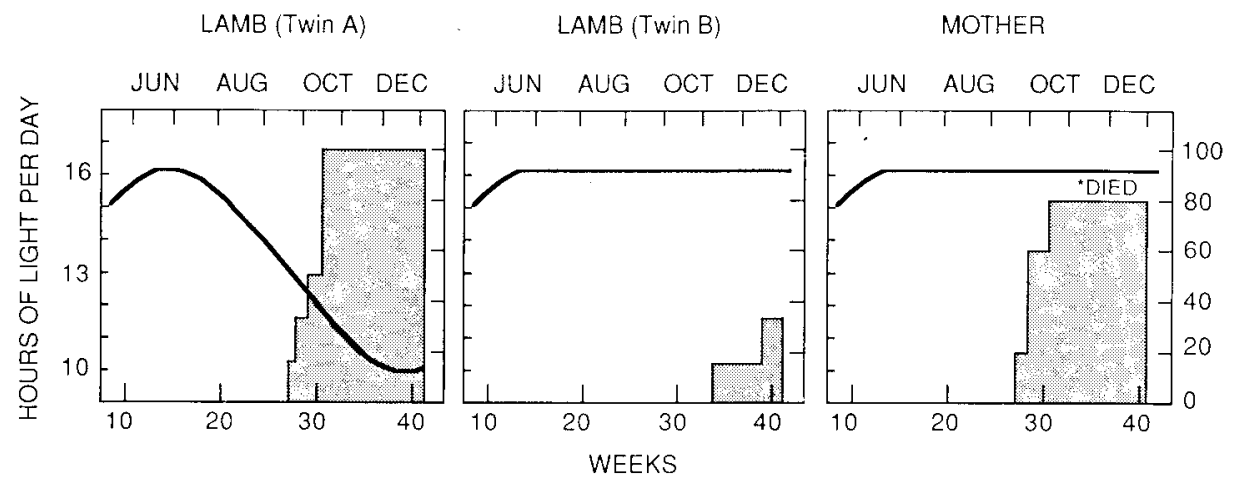

FIG. 3. - Initiation of neuroendocrine reproductive activity in artificial photoperiod in spring-born Suffolk twin lambs raised in (left) simulated natural photoperiod, $n=6$ (middle), long days from the summer solstice, $n=6$ and in (right) their mothers in long days from the summer solstice, $n=6$. The females were ovariectomized and implanted with a Silastic capsule of estradiol at 14 weeks of age (June); circulating LH was used to assess the neuroendocrine potential for reproduction with low LH concentrations reflecting the prepubertal or anestrus condition and high LH the postpubertal or breeding season condition. Data from Ebling and Foster (1987). 


\section{Long-day and short-day photoperiod requirements.}

Constant vs alternating photoperiods. - The failure of puberty to occur at the normal time in lambs reared continually in long days from birth (Yellon and Foster, 1985) or from 15 weeks of age following increasing natural day lengths (fig. 3 , middle) provides evidence that the spring-born lamb requires short days for the normal timing of puberty. Such observations raised the possibility that early exposure to short days might induce precocious puberty. This is not the case. Lambs reared only in short days also do not exhibit normal puberty (fig. 4, top) ; rather, it is delayed and occurs during the second year (Yellon and Foster, 1985). Interestingly, some long days are required as demonstrated by the normal initiation of reproductive cycles in short days when previously exposed to 10 weeks of long days (fig. 4, bottom). Even as little as one week of long days produces reproductive cycles in short days at the appropriate age, although they tend to be irregular and often consist of abbreviated luteal phases (Yellon and Foster, 1985). Finally, it should be noted that a prior experience of short days is not necessary for the young lamb to recognize long days. Lambs raised initially on long days from birth and then exposed to short days beginning at 22 weeks of age, do not exhibit delayed puberty (Foster and Yellon, 1986). Thus, a critical photoperiod requirement for the normal timing of puberty appears to be a change in day length, namely long days followed by short days.

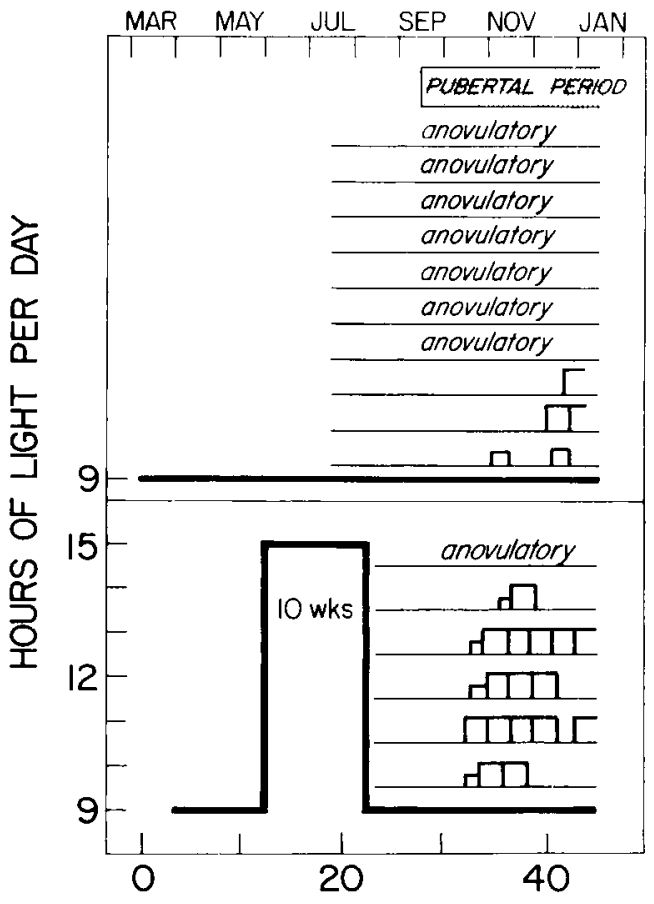

AVERAGE AGE (weeks)
FIG. 4. - Initiation of reproductive cycles in spring-born Suffolk lambs raised in artificial photoperiod. Top. Short days only. Bottom. Short day-long dayshort day sequence. Each horizontal line shows data for an individual female with large and small blocks representing normal and short luteal phases, respectively. Modified from Yellon and Foster (1985). 
FIG. 5. - Initiation of reproductive cycles in spring-born Suffolk lambs raised in artificial photoperiod sequences of short days, long days, short days. Top Mean \pm SEM age at onset of cycles in various years (number of lambs indicated in parentheses) for lambs with normal pineal gland function. Middle. Reproductive cycles in lambs in which the pineal gland was sympathetically denervated (SGX) after exposure to long days. Bottom. Reproductive cycles following denervation of the pineal gland before exposure to long days. Each horizontal line shows data for an individual female with each large block representing a normal luteal phase. Data from Yellon and Foster (1985, 1986), Foster and Yellon (1986, 1987), Foster et al. (1987a).

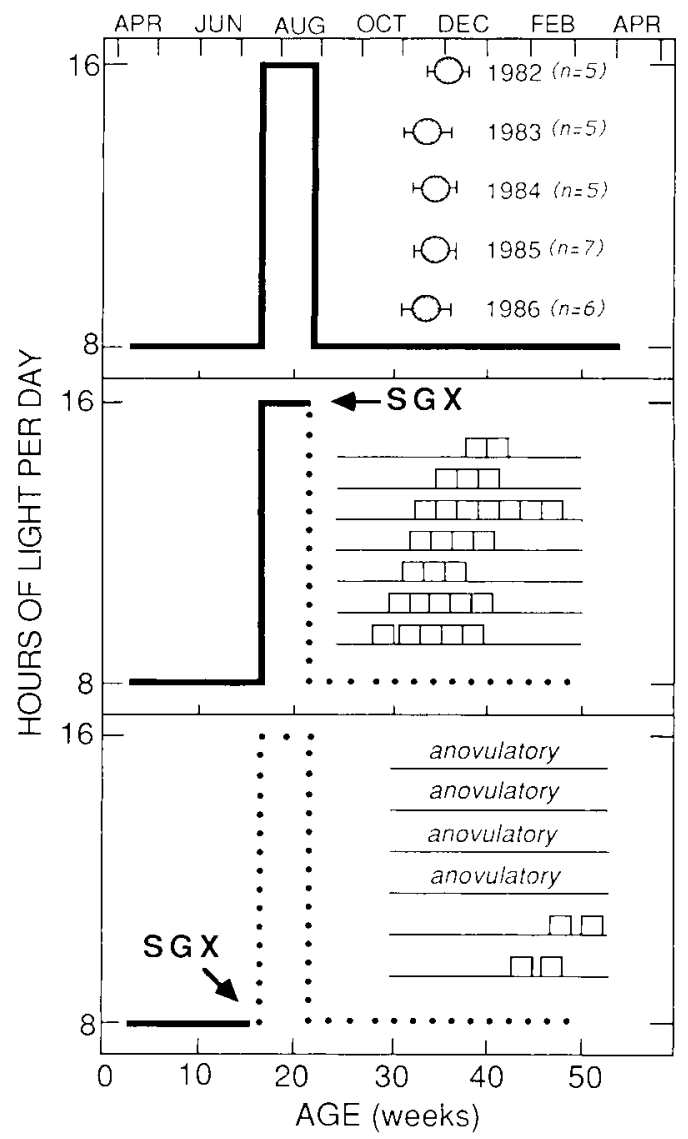

Selective removal and replacement of photoperiod information. - In addition to the use of artificial light treatments, selective removal and replacement of photoperiod information has provided a powerful technique to study the photoperiod requirements for puberty. As illustrated earlier (fig. 1), denervation of the pineal gland by ganglionectomy early in life markedly retards onset of repetitive reproductive cycles. This is due to the lack of long-day, rather than short-day information (Yellon and Foster, 1986 ; Foster and Yellon, 1986 ; Foster et al., 1987a). Ganglionectomy of lambs after exposure to long days is without effect on the timing of puberty (fig. 5, midd/e), but disruption of photoperiod cues before treatment with long days delays onset of ovulations (fig. 5, bottom). These findings indicate that once the critical long-day information is obtained, a sequence of neuroendocrine events is set in motion for normal puberty which does not require the presence of ambient short days.

The apparent lack of a requirement for short days during the early or late stages of sexual maturation for the timing of normal puberty raises an intriguing possibility. Perhaps the female sheep, a classical " short-day » breeder, does not 
require ambient short days for normal puberty. This hypothesis was tested more directly with lambs raised only in long days where the time of exposure to longday information was carefully regulated (fig. 6). Interruption of the mechanism for transmission of long-day information shortly after birth by ganglionectomy delays puberty (fig. 6, left), a finding consistent with other treatments which failed to provide long days (fig. 4, top, short days only; fig. 5, bottom, ganglionectomy before long days). However, blockade of long-day information after 23 weeks of long days does not disrupt the normal timing of puberty despite the total lack of any exposure to short days (fig. 6, middle). Finally, infusion of melatonin in a long-day pattern ( 8 hours/night) for 5 weeks into neonatally ganglionectomized lambs (fig. 6, right) prevents the delay in puberty experienced by lambs receiving no long-day information (fig. 6, left). Thus, experimentally, long-day exposure followed by blockade of long-day information is sufficient for normal timing of puberty. However, it is entirely possible that artificial removal of long days by surgical ganglionectomy after long-day pretreatment provides exactly the same seasonal time cue as exposure to a decreasing photoperiod under natural conditions.
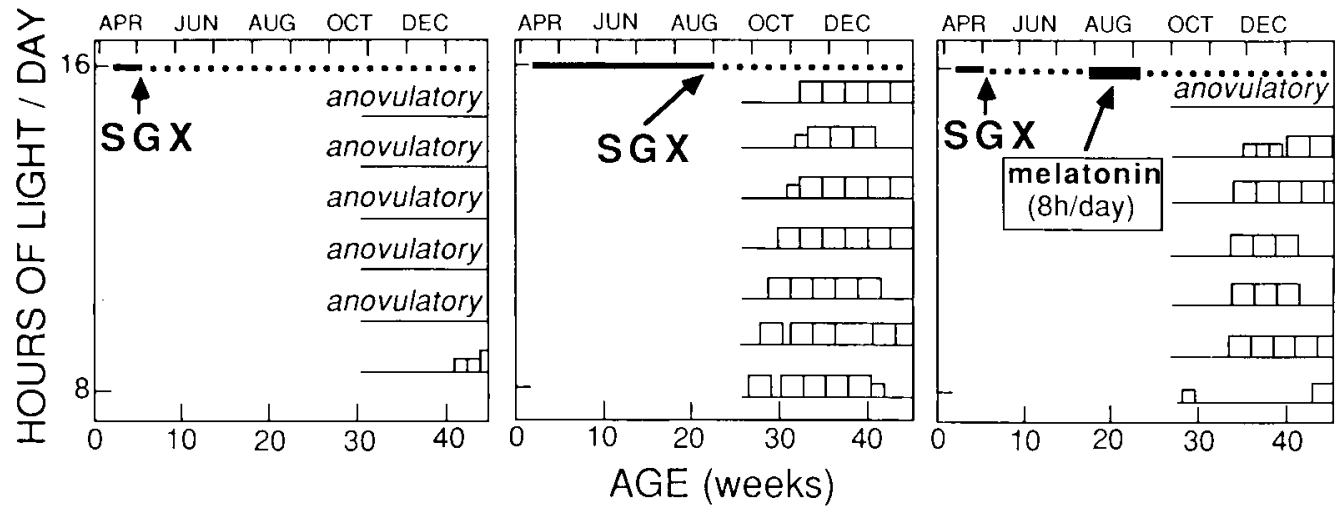

FIG. 6. - Initiation of reproductive cycles in spring-born Suffolk lambs raised entirely in artificial long days. The pineal gland was denervated sympathetically (SGX) either at 3-4 weeks of age (left and right pane/s) or 23 weeks of age (middle panel). Lambs in right pane/ were infused with melatonin for 8 hours nightly for 5 weeks (18-23 weeks of age). Each horizontal line shows data for an individual female with large and small blocks representing normal and short luteal phases, respectively. Data from Foster et al. (1987a).

Novel hypothesis for timing puberty by photoperiod. - In view of all of the foregoing considerations, the hypothesis for timing of puberty in the spring-born female sheep (Foster et al., 1986) can be further refined and expanded (fig. 7). Exposure to short days during early postnatal life is not necessary to recognize subsequent long day lengths. However, once the lamb has experienced some long days, a sequence of neuroendocrine events is set in motion that can lead to puberty. Continued exposure to long days does not permit this to occur at a normal rate. The presence of short days does. Moreover, the normal initiation of reproductive cycles after long days can occur in the absence of any further 
photoperiod information. Taken together, these findings raise the possibility that in natural conditions, the short days of autumn are merely permissive to puberty. Accordingly, it would be the long days of summer followed by their disappearance that time puberty in the spring-born lamb.

FIG. 7. - Schematized hypothesis for photoperiod requirements for the timing of puberty in the spring-born female lamb wherein exposure to long days followed by their removal is critical to the normal initiation of reproductive cycles. See text for rationale for the hypothesis.
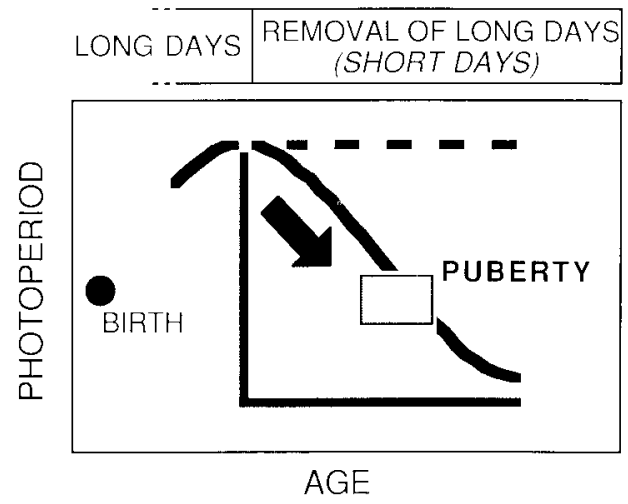

Early exposure to long days - Failure to induce precocious puberty. - The requirement of the lamb for some long-day exposure for the normal timing of puberty provides insight into why lambs raised entirely in short days do not exhibit precocious onset of reproductive function. Moreover, only a brief exposure to long days $(10,5$, or 1 week) ending at 22 weeks of age is needed to initiate cycles 10-14 weeks later (32-36 weeks of age). With this understanding, we have begun to explore when in development long days are first able to induce subsequent puberty in short days. Perhaps long days, if experienced at a very early age, would induce precocious puberty. This is not the case. Exposure to long days during the neonatal period is virtually ineffective ; puberty does not occur early, and in fact, it is delayed. For example, whereas as little as one week of long days at 22 weeks of age produces substantial reproductive activity in subsequent short days (fig. 8, top), four weeks of long days shortly after birth followed by short days does not (fig. 8, bottom). As many as 10 weeks of long days in the early postnatal period were only capable of inducing repetitive reproductive cycles in a minority of lambs (2 of 6, Yellon and Foster, 1985).

This ineffectiveness of long-day exposure in the neonate to induce even normal puberty might be due to a) prepineal or pineal gland immaturity - an inability of the pineal gland to receive or transduce photoperiod information ; b) postpineal gland immaturity - an inability of the reproductive axis to respond to photoperiod information. The first hypothesis is less attractive in view of recent evidence that the very young lamb can alter its melatonin secretion to accord with the light-dark cycle. Measurement of circulating melatonin for 24-48 hours at 1 and 6 weeks of age (fig. 9) revealed that the daily melatonin rise was already established in most lambs and that its duration corresponded to the dark phase of the photoperiod (L. E. Claypool, R. I. Wood, F. J. P. Ebling and 


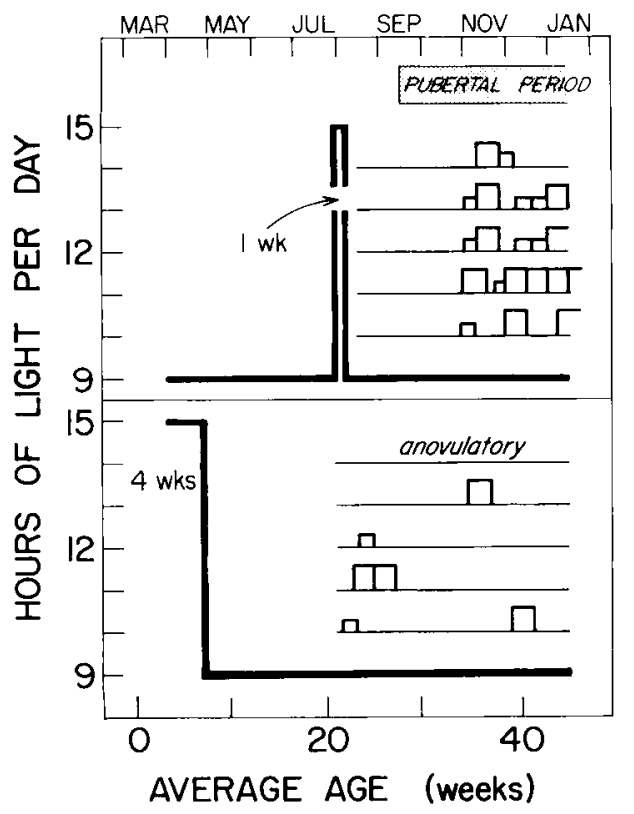

FIG. 8. - Initiation of reproductive cycles in spring-born Suffolk lambs exposed to long artificial photoperiods during the (bottom) neonatal period or (top) later stages of sexual maturation. Each horizontal line shows data for an individual female with large and small blocks representing normal and short luteal phases, respectively. Modified from Yellon and Foster (1985).

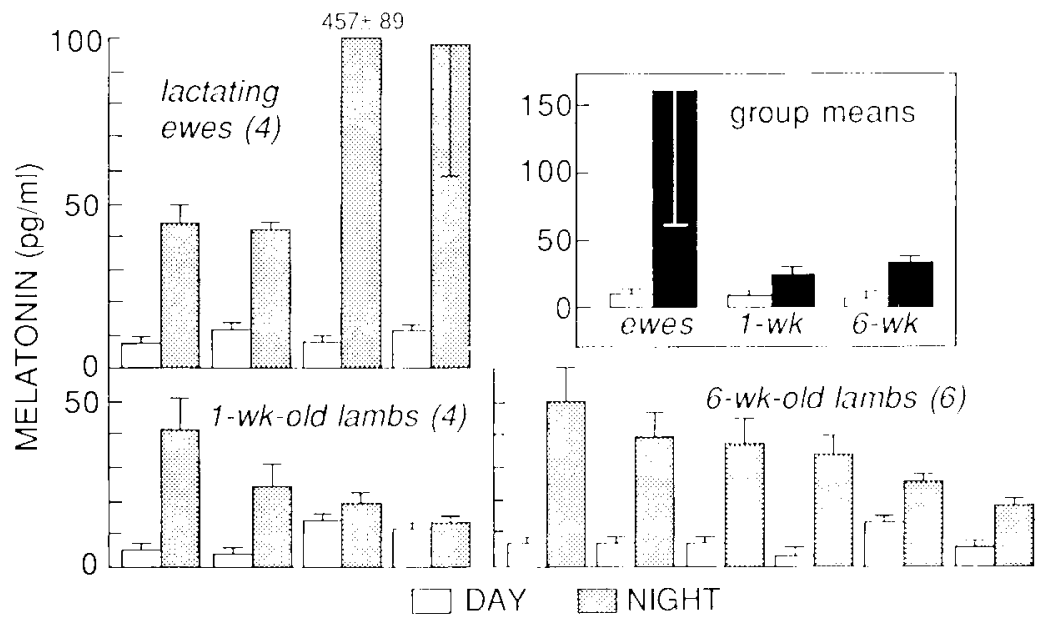

FIG. 9. - Circulating melatonin during a 24-hour period in (bottom) female Suffolk lambs at one (left ; $\mathrm{n}=4$ ) and six (right ; $\mathrm{n}=6$ ) weeks of age and (top) in the lactating ewes ( $\mathrm{n}=4$ ) one week after parturition. Means \pm SEM for each female during the day (open bar) and night (dark bar) are presented. Data from L. E. Claypool, R. I. Wood, F. J. P. Ebling and D. L. Foster (unpublished). 
D. L. Foster, unpublished). Such a nocturnal melatonin rise has been found even before birth (Yellon and Longo, 1987); this raises the possibility that information about photoperiod may reach the conceptus in utero as demonstrated in some rodent species (Horton 1984, 1985 ; Stetson et al., 1986). However, whether the melatonin rhythm of the fetus is endogenous or reflects transplacental passage of the hormone from the maternal pineal gland remains to be determined. In the neonatal lamb, the rhythm is endogenous because : a) insufficient quantities of melatonin are present in milk to account for those found in the circulation of the lamb $; b)$ when mothers and lambs are transferred from a long to a short photoperiod, the time taken for the melatonin rhythm to entrain to the new light-dark cycle may differ between the mother and her lamb ; and $c$ ) the pattern of melatonin is not disrupted after weaning (R. I. Wood, L. E. Claypool, F. J. P. Ebling and D. L. Foster, unpublished). Thus, it is likely that at a relatively early age the pineal gland has attained an important adult function, namely the ability to secrete melatonin for the duration of the dark phase of the daily photocycle. Although the amplitude of melatonin secretion appears to be lower in the 1-and 6-week-old lamb than in the adult ewe (fig. 9), there is good evidence that the neonatal lamb can use this melatonin signal, based upon prolactin secretion as a measure of photoperiod responsiveness (Foster et al., 1987a). In two separate experiments, we have determined that lambs raised under artificial long days for the first 10 weeks have higher circulating concentrations of prolactin than do those under short days during this period. Furthermore, superior cervical ganglionectomy abolishes this difference, suggesting an important photoneuroendocrine response system involving the pineal gland is established by at least the early postnatal period.

The balance of evidence accumulated thus far suggests that the lamb can determine the presence of long days, and therefore, other explanations must hold for their ineffectiveness early in life to produce early initiation of reproductive function. One is an immaturity of mechanisms whereby photoperiod information is conveyed to the reproductive axis or immaturity of the reproductive system itself. At present, it is not possible to distinguish between the two possibilities, although evidence has accumulated that many components of the ovulatory mechanism are mature well before the normal age of puberty (e.g., follicle response to gonadotropin, preovulatory gonadotropin surge system) (Foster et al., 1986). Perhaps, at very early ages, the failure of long days to induce ovulatory cycles in subsequent short days may not be due to photoperiod unresponsiveness, but rather to inadequate growth. For example, exposure to artificial long days followed by their withdrawal during the first 6 weeks may set a photoperiod mechanism in motion which perceives the ending of long days as " autumn ". Ten-12 weeks later (latent period) when the response, first ovulation, should occur it cannot. According to the hypothesis being developed, body size is inadequate to begin reproduction; under these circumstances internal cues (metabolic) related to small size or inappropriate growth override those external, seasonal cues such as photoperiod.

While the foregoing hypothesis awaits rigorous testing, some evidence exists that during inadequate growth, photoperiod cues can be perceived, but the 
response cannot be expressed until growth is more rapid. In this regard, photoperiod time measurement is maintained in growth-retarded lambs with delayed puberty (Foster and Yellon, 1985). In the model system used, growth was slowed by reducing the level of nutrition in estradiol-treated ovariectomized lambs (fig. 10). Before resumption of growth by feeding ad libitum, one group was exposed to long days (fig. 10, bottom) while the other to short days (fig. 10, top). Both groups were then maintained on short days, and the level of nutrition was increased. Only the group experiencing long days before short days exhibited neuroendocrine sexual maturation, an increase in $\mathrm{LH}$ secretion resulting from a decrease in sensitivity to estradiol inhibition. Thus, when body size was small, the critical long-day information was perceived, and the long day-short day photoperiod sequence resulted in neuroendocrine puberty once they had achieved sufficient physiologic size to permit reproductive activity to be expressed. Perhaps

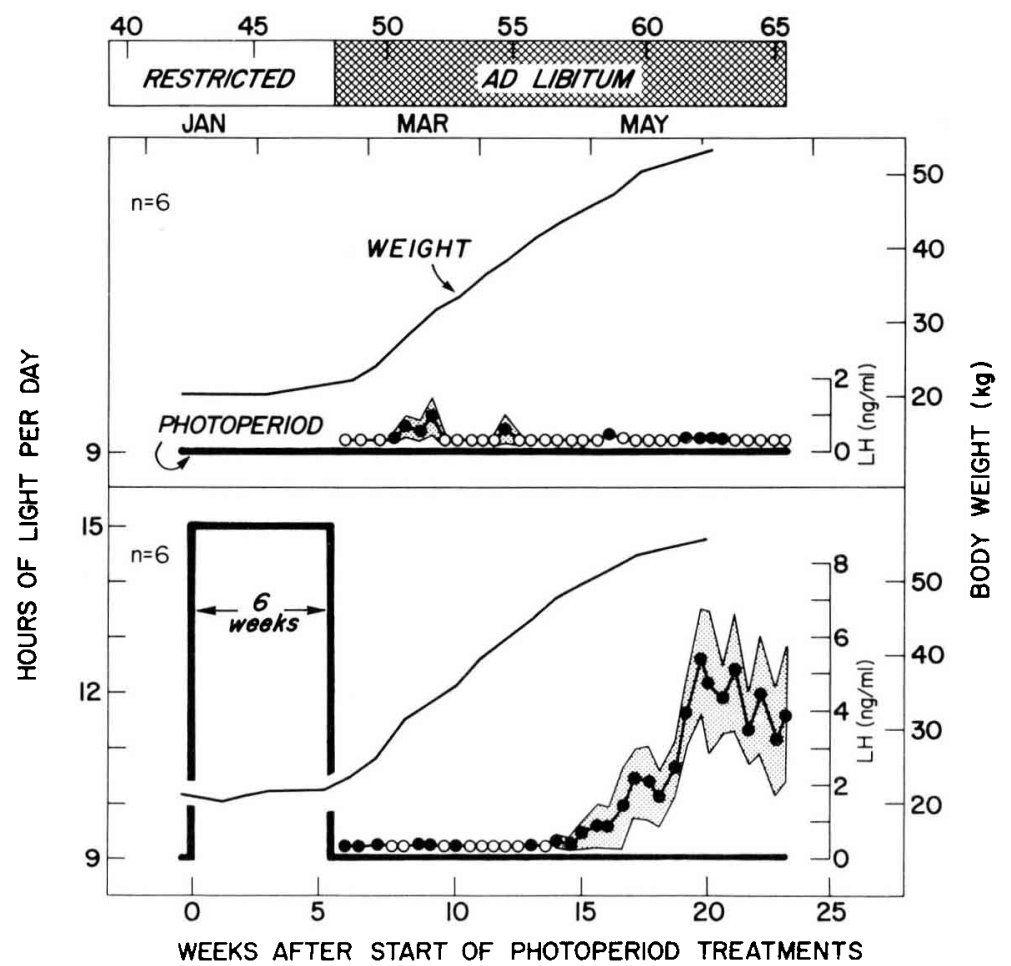

FIG. 10. - Demonstration that photoperiod time measurement is operative at small body size, but that reproductive response cannot occur until an advanced stage of growth is achieved. Mean \pm SEM LH concentrations were monitored in female Suffolk lambs in artificial short days during ad libitum feeding after having been exposed while on a restricted diet to (top) short days or (bottom) long days for 5 weeks. The females had been ovariectomized at 20 weeks of age, and for this experiment, chronically treated with estradiol at the start of the ad libitum diet. From Foster and Yellon (1985). 
in the young lamb, precocious puberty might be induced with a long-day to shortday transition during the neonatal period if subsequent growth could be enhanced beyond " normal " so that the developing female could respond reproductively to the photoperiod information earlier. Finally, in our previous study (fig. 8, bottom), it seems plausible that by the time the lambs had reached sufficient body size to allow a reproductive response to photoperiod, the period of exposure to short days following the neonatal long-day treatment was so long that refractoriness to short days would have developed; this could explain their delayed puberty.

Other examples exist of such interactions between growth-related, and photoperiod cues. This is exemplified in figure 11 which depicts the age and weight at puberty in spring-born lambs in which growth rate was regulated by level of nutrition. In normally growing females (Group A), reproductive cycles were initiated during the decreasing day lengths of autumn. Other lambs (Groups B and $\mathrm{C}$ ), in which quantity of diet was initially restricted, attained
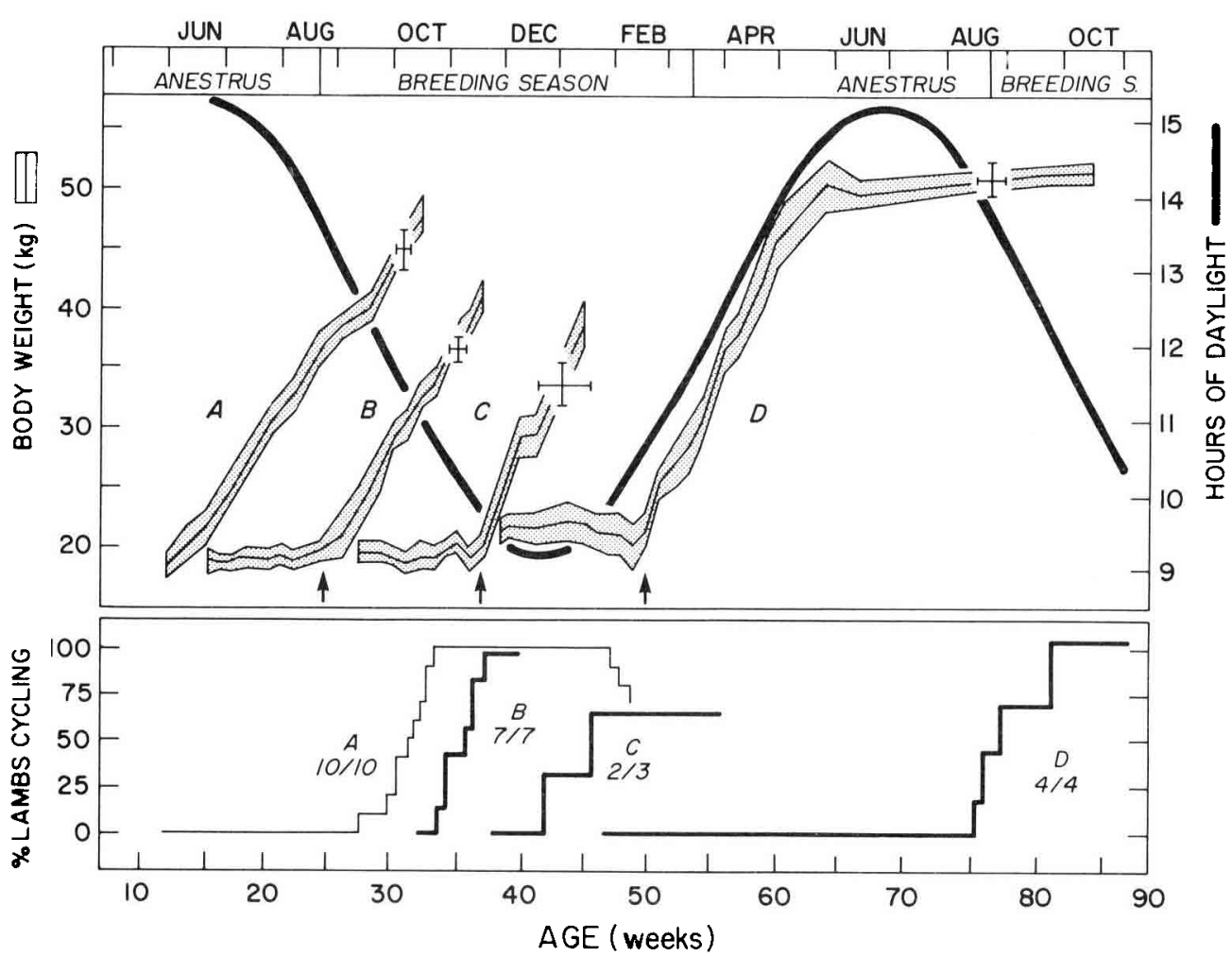

FIG. 11. - Influence of season and growth on the initiation of reproductive cycles in the spring-born Suffolk lamb raised outdoors (top, mean \pm SEM ; bottom, individuals, histograms). They were either (A) fed ad libitum after weaning at 10 weeks of age or were (B, C, D) placed on a restricted diet of similar composition and then fed ad libitum beginning at various ages (arrows). The general limits of the anestrus and breeding seasons of the adult female are indicated. From Foster et $a l_{.}, 1985$. 
puberty during their growth spurt induced by feeding ad libitum. However, they were smaller, suggesting that the timing of first ovulation in the normal group (A) was ultimately regulated by photoperiod, rather than size ; as inferred earlier from artificial photoperiod treatments, ovulations began in response to the long days of spring and summer followed by their disappearance in autumn. Finally, lambs in which the phase of rapid growth was forestalled until after the winter solstice did not attain puberty during the first year (Group D). The appropriate size was attained during long days, but first reproductive cycles did not begin until the onset of the adult breeding season. Perhaps, this latter group of young females initiated reproductive cycles because they developed refractoriness to the long days of summer - the adult photoperiod response. If this were the case, then it raises the possibility that first ovulation in lambs occurs in response to one of two distinctly different photoperiod cues. Normally growing spring-born lambs begin in response to removal of long days, whereas those which do not because of growth limitations, begin the :following year in response to long-day photorefractoriness. Because this latter response is characteristic of the adult, it raises the possibility that such lambs attain sexual maturity during the summer and immediately become seasonaily anestrus without exhibiting first ovulation. Thus, the transition into adulthood would be masked, and the initiation of reproductive cycles would reflect onset of a breeding season, rather than onset of puberty itself. Of equal importance, this latter model may well hold for the autumn-born lamb which also attains the appropriate size for puberty during the long days of the summer anestrous season (fig. 2, middle); arguments have been made earlier that the initiation of reproduction in the autumn-born lamb is a transition from postmaturational seasonal anestrus (Foster, 1981).

If the ability to begin reproductive cycles in response to long-day photorefractoriness is a postpubertal characteristic, then how does this phenomenon develop? Little is known about this, and the reader is referred to the chapters by Robinson and Karsch (1988) ; Karsch et al. (1988) for the present understanding of endogenous reproductive rhythms in the adult and how they are phased by photoperiod cues. Recently, we have discovered that young female lambs with late "puberty " can also initiate their first reproductive cycles by becoming refractory to long days (Foster and Yellon, 1986 and unpublished). When such lambs were raised for the first 17 weeks in short days, transfer to long days delayed onset of first ovulation (fig. 12). Then, at 40 weeks of age, about two months, after the normal age of puberty, reproductive cycles began synchronous/y amongst the young females despite the continued presence of long days. Our interpretation of this finding is similar to that for the other situations indicated above when appropriate body size is attained during long days after having been exposed previously to short days. Sexual maturity is first masked and is then expressed by the transition from postmaturational anestrus to the onset of breeding activity in response to becoming refractory to long-day inhibition. The ability to become refractory to long days appears to be facilitated by previous exposure to short days. This is because lambs born in spring and raised entirely in long days (Yellon and Foster, 1985) or in long days after increasing day lengths (fig. 3) exhibit only poor synchrony of first ovulation, and 
cycles are irregular which is in distinct contrast to those which first experience short days (fig. 12).

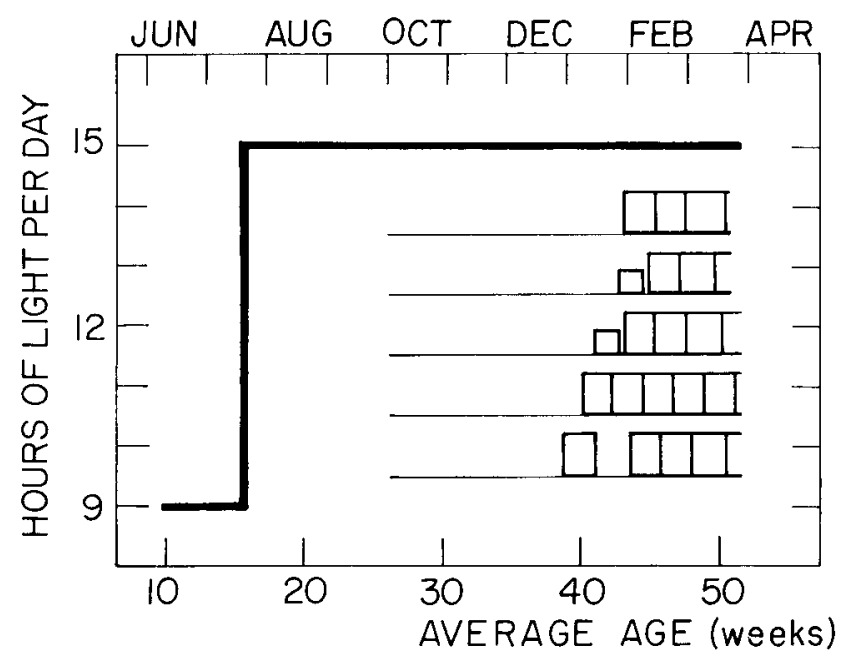

FIG. 12. - Initiation of reproductive cycles in spring-born Suffolk lambs raised first in short-day and then in long-day artificial photoperiod. Each horizontal line shows data for an individual female with large blocks and small blocks representing normal and short luteal phases, respectively. Data from Foster and Yellon, 1986 and unpublished.

\section{Conclusions.}

We are beginning to realize that the timing of first ovulation by photoperiod cues in the young female sheep is not as simple as once thought. Exactly when the period of sexual maturation is completed is often obscured by factors such as growth rate and season of birth. The lamb has but a few months to determine if it has been born at the appropriate time of year so that its trajectory of growth will result in sexual maturity in the appropriate season to begin reproduction. It has but a limited photoperiod history with which to evaluate the progress of seasons ; a single directional change, long days to short days, provides a key cue that attainment of puberty at that time of year will be reproductively successful. In contrast to the lamb, the postpubertal, mature female has a much longer history of photoperiod information. We have come to recognize that its annual drive to reproduce is inherent and based upon an endogenous rhythm of reproductive activity. Although it is entrained to the appropriate season by the change in daylength, it can be expressed even in the absence of a change in photoperiod. Ducker et al. (1973) suggested that onset of reproductive activity is innate in the lamb ; our observations that manipulation of photoperiod can alter the timing of 
puberty, but never delay it indefinitely, support this general conclusion. We propose that once internal growth-related cues indicate an adequate size has been attained and the endogenous reproductive rhythm is able to be expressed, the photoperiodic mechanism is fundamentally the same in the lamb and the adult. Photoperiod acts to entrain the endogenous reproductive rhythm to the appropriate season. The actual differences in photoperiod requirements for the first and subsequent breeding seasons may simply reflect the fact that the springborn lamb does not have an extensive photoperiodic history, and thus, its innate reproductive rhythm is not entrained to the environment. The decrease in photoperiod, whether by experimental removal of long days or by exposure to decreasing photoperiod, is critical as the first seasonal cue in the life of the female sheep.

Colloquium on "Neuroendocrine mechanisms and light control of reproduction in domestic mammals ") I.N.R.A., Nouzilly, 17-18 September 1987.

Acknowledgements. - For critical discussion of experimental design and results, we are thankful to numerous colleagues including F. J. Karsch, B. Malpaux, Deborah H. Olster, Jane E. Robinson, Nancy L. Wayne, Ruth I. Wood and S. M. Yellon. For technical assistance with animal experimentation, we are indebted to D. D. Doop and for laboratory services to Tovaghgol E. Adel. The support of the Sheep Research Core Facility in the husbandry, the Standards and Reagents Core Facility in providing quality materials for radioimmunoassays, and Diane $E$. Belleba and Betty $C$. Lewis for manuscript typing are gratefully acknowledged. This work has been funded by grants from the National Institutes of Health, Washington D. C.

\section{Résumé. Réglage du moment de la puberté par la photopériode.}

Les informations photopériodiques jouent un rôle important sur le moment d'apparition de la puberté chez l'agnelle. L'abolition et le remplacement des informations photopériodiques, respectivement par la dénervation de la glande pinéale ou par des infusions contrôlées de mélatonine, indiquent que le circuit qui permet le passage de l'information de la photoperiod, whether by experimental blockade of long days or by exposure to photopériodes artificielles à différents moments du développement. De telles approches révèlent que, même au cours des tous premiers jours de la vie, le mode de sécrétion de la mélatonine est en accord avec la durée du jour et module la sécrétion de prolactine. Plusieurs mois plus tard, lorsque les informations internes liées à la croissance indiquent qu'une taille suffisante a été atteinte pour commencer la reproduction, le passé photopériodique est utilisé pour prédire le succès de la reproduction et ainsi savoir si la puberté peut se produire. Chez l'agnelle née au printemps, la décroissance de la durée du jour en automne est l'information primordiale de l'initiation des cyles ostriens. Expérimentalement, ceci peut être réalisé en coupant chirurgicalement le circuit de transmission des informations photiques après une exposition appropriée à des jours longs. Chez !'agnelle née en automne et chez celle à croissance lente, la maturation sexuelle peut être masquée par l'anœstrus saisonnier au printemps suivant. Chez ces jeunes femelles, une décroissance de la photopériode ou le retrait des jours longs (chirurgicalement) n'est pas nécessaire à l'apparition de la puberté à l'automne suivant. Un passé photopériodique suffisant a pu être acquis par ces femelles pour qu'elles entrent en puberté en devenant réfractaires aux jours longs d'été. Ce phénomène de photoréfraction reflète probablement l'expression d'un rythme endogène d'activité de reproduction, et les changements de durée du jour enregistrés au début de la vie serviraient à synchroniser ce rythme avec l'environnement saisonnier. 


\section{References}

DUCKER M. J., BOWMAN J. C., TEMPLE A., 1973. The effect of constant photoperiod on the expression of oestrus in the ewe. J. Reprod. Fert., Suppl., 19, 143-150.

EBLING F. J. P., FOSTER D. L., 1987. Photoperiod requirements for puberty differ from those for onset of the adult breeding season in sheep. Biol. Reprod, Suppl. 1, 36, p. 160 (Abstr. \# 341).

FOSTER D. L., 1981. Mechanism for delay of first ovulation in lambs born in the wrong season (Fall). Biol. Reprod, 25, 85-92.

FOSTER D. L., 1987. Puberty in the female sheep. In The physiology of reproduction, 1739-1762. Eds E. KNOBIL \& J. D. NEILL, Raven Press, New York.

FOSTER D. L., RYAN K. D., 1981. Endocrine mechanisms governing transition into adulthood in female sheep. J. Reprod. Fert., Suppl., 30, 75-90.

FOSTER D. L., YELLON S. M., 1985. Photoperiodic time measurement is maintained in undernourished lambs with delayed puberty. J. Reprod. Fert., 75, 203-208.

FOSTER D. L., YELLON S. M., 1986. Normal puberty in the female sheep in the absence of prevailing photoperiod cues. Biol. Reprod., Suppl. 1, 34, p. 79 (Abstr. \# 59).

FOSTER D. L., YELLON S. M., 1987. Absence of an increase in gonadal-independent drive to pulsatile luteinizing hormone secretion during photoperiod-induced puberty. Biol. Reprod. 37, 634-639.

FOSTER D. L., OLSTER D. H., YELLON S. M., 1985. Neuroendocrine regulation of puberty by nutrition and photoperiod. In Adolescence in females, 1-21. Eds C. FLAMIGNI, S. VENTUROLI and J. R. GIVENS, Year Book Medical Publ., Chicago.

FOSTER D. L., KARSCH F. J., OLSTER D. H., RYAN K. D., YELLON S. M., 1986. Determinants of puberty in a seasonal breeder. Rec. Prog. Horm. Res., 42, 331-384.

FOSTER D. L., EBLING F. J. P., CLAYPOOL L. E., 1987a. Normal timing of puberty in a short-day breeder in the absence of ambient short days. Biol. Reprod., Suppl. 1, 36, p. 160 (Abstr. \# 340).

FOSTER D. L., EBLING F. J. P., CLAYPOOL L. E., 1987b. Neuroendocrine responsiveness to light during the neonatal period in the sheep. Endocrinology, 120. Suppl., p. 59 (Abstr. \# 151).

HORTON T. H., 1984. Growth and reproductive development of male Microtus montanus is affected by the prenatal photoperiod. Biol. Reprod., 31, 499-504.

HORTON T. H., 1985. Cross-fostering of voles demonstrates in utero effects of photoperiod. Biol. Reprod., 33, 934-939.

KARSCH F. J., BITTMAN E. L., FOSTER D. L., GOODMAN R. L., LEGAN S. J., ROBINSON J. E., 1984. Neuroendocrine basis of seasonal reproduction. Rec. Prog. Horm. Res., 40, 185-225.

KARSCH F. J., MALPAUX B., WAYNE N. L., ROBINSON J. E., 1988. Characteristics of the melatonin signal that provide the photoperiodic code for timing seasonal reproduction in the ewe. Reprod. Nutr. Dévelop., 28, 459-472.

KENNAWAY D. J., GILMORE T. A., DUNSTAN E. A., 1985. Pinealectomy delays puberty in ewe lambs. J. Reprod. Fert., 74, 119-125.

ROBINSON J. E., WAYNE N. L., KARSCH F. J., 1985. Refractoriness to inhibitory day lengths initiates the breeding season of the Suffolk ewe. Biol. Reprod., 32, 1024-1030.

ROBINSON J. E., KARSCH F. J., 1988 . Timing the breeding seascn of the ewe : what is the role of daylength ? Reprod. Nutr. Dévelop., 28, 365-374.

STETSON M. H., ELLIOTT J. A., GOLDMAN B. D., 1986. Maternal transfer of photoperiodic information influences the photoperiodic response of prepubertal Djungarian hamsters. Biol. Reprod., 34, 664-669.

YELLON S. M., FOSTER D. L., 1985. Alternate photoperiods time puberty in the female lamb. Endocrinology, 116, 2090-2097.

YELLON S. M., FOSTER D. L., 1986. Melatonin rhythms time photoperiod-induced puberty in the female lamb. Endocrinology, 119, 44-49.

YELLON S. M., LONGO L. D., 1987. Melatonin rhythms in fetal and maternal circulation during pregnancy in sheep. Am. J. Physiol., 252, E799-E802. 